\title{
Initial Challenges of Caregiving During COVID-19: Caregiver Burden, Mental Health, and the Parent-Child Relationship
}

\author{
B. S. Russell ${ }^{1}$ (1) $\cdot$ M. Hutchison ${ }^{1} \cdot$ R. Tambling ${ }^{1} \cdot$ A. J. Tomkunas ${ }^{1} \cdot$ A. L. Horton ${ }^{1}$
}

Published online: 4 August 2020

(c) Springer Science+Business Media, LLC, part of Springer Nature 2020

\begin{abstract}
Research confirms that the mental health burdens following community-wide disasters are extensive, with pervasive impacts noted in individuals and families. It is clear that child disaster outcomes are worst among children of highly distressed caregivers, or those caregivers who experience their own negative mental health outcomes from the disaster. The current study used path analysis to examine concurrent patterns of parents' $(n=420)$ experience from a national sample during the early months of the U.S. COVID-19 pandemic. The results of a multi-group path analysis, organized by parent gender, indicate good fit to the data $\left[\mathrm{X}^{2}(10)=159.04, \mathrm{p}<.01\right]$. Results indicate significant linkages between parents' caregiver burden, mental health, and perceptions of children's stress; these in turn are significantly linked to child-parent closeness and conflict, indicating possible spillover effects for depressed parents and compensatory effects for anxious parents. The impact of millions of families sheltering in place during the COVID-19 pandemic for an undefined period of time may lead to unprecedented impacts on individuals' mental health with unknown impacts on child-parent relationships. These impacts may be heightened for families whose caregivers experience increased mental health symptoms, as was the case for fathers in the current sample.
\end{abstract}

Keywords Caregiver burden $\cdot$ Depression $\cdot$ Anxiety $\cdot$ Parent-child relationship $\cdot$ COVID-19

\section{Introduction}

COVID-19 arrived in the United States early in 2020 and quickly altered the daily routines of families nationwide as shelter-in-place recommendations took hold, schools and child care centers closed their physical buildings, and a significant portion of the workforce shifted operations to reduced or remote work from home routines. COVID-19 is a novel, highly contagious but preventable disease caused by a coronavirus (SARS-CoV-2) [1], mortality rates for COVID-19 have surpassed 362,705 deaths worldwide and 103,700 deaths in the United States in May 2020, exceeding rates seen for other recent flu and SARS epidemics [2-4]. Time-sensitive research identifies COVID-19-related stressors including fears of infection, disruptions to work/learning and daily self-care routines, and lack of access to reliable information and resources [5]. Reports from families during

B. S. Russell

beth.russell@uconn.edu

1 Department of Human Development \& Family Sciences, University of Connecticut, 348 Mansfield Road, Unit 1058, Storrs, CT 06269-1058, USA the peak of COVID-19 in the U.S. indicate these stressors are heightened for those caring for children [5-8], though little is known about how this increased stress will impact child-parent relationships [9]. The pattern of affect and behavior that can spillover from parents to children may take several forms, as described by Nelson et al. [10]: the spillover hypothesis suggests that affect or behavior can transfer with the same valence within a family system from one relationship to another (i.e., negative affect in the parent is linked to negative affect in the child). A second such impact, called the compensatory hypothesis, suggests that the transfer between family subsystems can occur in the opposite valence, to compensate or protect against negative affect. A final similar process is described as a crossover, where rather than a transfer of affect within one person across subsystems, crossover refers to the transfer of affect or behavior between people (e.g., when the co-parenting stress experienced by one caregiver crosses over to impact the other partner's relationship with their child).

Research confirms that the mental health burdens following community-wide disasters are extensive, with pervasive impacts noted in individuals and families [11]. Among public health officials' COVID-19 recommendations [12] 
to slow the spread of the disease, in addition to a period of quarantine has been instituted in many municipalities, as of this writing on May 25, 202048 states, 4 U.S. territories, and Washington D.C. had issued notices that all K-12 schools will remain physically closed for the duration of the 2019-2020 academic year, these closures will impact roughly 55.8 million public and private school students [13]. Experts caution that the COVID-19 pandemic is an instance of traumatic stress and will likely worsen existing mental health difficulties and lead to the development of new disorders in others for an extended period of time [14, 15]. It is clear that exposure to a wide range of disasters negatively impacts mental health and can lead to prolonged periods of increased psychiatric symptomology, including anxiety and depression [16-20]. Further evidence suggests that child disaster outcomes are worst among children of highly distressed caregivers, or those caregivers who experience their own negative mental health outcomes from the disaster [21-23].

During epidemic conditions, quarantine-related stressors that impact mental health outcomes include prolonged duration of isolation, infection fears, frustration, boredom, inadequate supplies and information, financial loss, and stigma [24], which are associated with subsequent psychological disorders after brief quarantines of as little as 10 days [25]. The impact of millions of families sheltering in place for an undefined period of time during the current pandemic may lead to unprecedented impacts on individuals' mental health with unknown impacts on child-parent relationships. Periods of uncertainty with an indeterminant endpoint [26, 27], such as quarantines enacted during epidemics, constitute a stressful experience with particular salience for children [28]. When facing adversities like natural disasters, routines for daily activity contribute to stability and predictability which underpin children's mental health outcomes [29].

\section{Parenting Response to COVID-19}

Evidence suggests that compared to those with fewer caregiving responsibilities, parents experience potent, negative responses to disasters more acutely $[8,17]$. Anxiety and posttraumatic stress may be exacerbated in caregivers who feel an additional caregiving burden during disasters [21, 30]. Parents have an important role in shaping disaster outcomes for themselves, in terms of their own coping and self-care, and for their children by modeling coping responses as a primary source of children's coping socialization [31, 32]. For example, a recent study indicates that even when children report lower disaster exposure than their parents, they experienced similar general distress [33], underscoring reports of exacerbated negative child disaster outcomes among children of highly distressed caregivers [21-23]. In contrast, supportive parenting, confidence in safety, and discussions about the disaster can provide a buffer against children's subsequent mental health symptoms $[20,34]$, indicating positive, responsive parenting can play important protective roles in the development of children's stress-related symptoms [35, 36]. Responsive parenting is sensitive to children's needs by responding appropriately and consistently to children's cues [37], and significantly associated with children's positive psychosocial, cognitive, and behavioral outcomes [23, 38, 39].

In order to meet the unprecedented and indeterminate demands of parenting during COVID-19, parents must actively plan new caregiving, work, and education routines, potentially compromising time to tend to their own emotional experience and self-care. Family systems' theory and parenting research describes parents' role as complex [40, 41], given the need to attend and respond the needs of multiple family subsystems (individual self-care, coordination of co-parenting demands, and parenting needs). High levels of psychological distress and caregiver burden may complicate the resulting balance between parallel care responsibilities and create the potential for parents to sacrifice their own well-being to meet caregiving needs of their children, most often noted among mothers who frequently assume the primary caregiving role $[42,43]$. Parents' mental health symptoms may make this balance harder in two ways: (1) high levels of distress may interfere with parents' perceptions of their children's stress-and therefore impact responsive parenting - as seen in depressed and anxious mothers' overreporting of their children's psychiatric symptoms [44], and in withdrawn or unavailable patterns of parent-child interaction [36, 45, 46]. (2) Leveraging psychological resources to be resilient in the face of stressful challenges like COVID-19 is hampered by pre-existing mental health symptoms, which compromise the regulation of stress [5], including coping with the strains of caregiver burden.

The stresses and strains of parenting during disasters may amplify caregiver burden and mental health symptoms, potentially compromising parenting behavior sufficiently to impact the parent child relationship-a significant predictor of children's outcomes during times of prolonged stress [21-23]. However, there is resilience in family systems, too, as not all children of parents with mental health symptoms experience maladaptive outcomes [47], and brief periods of less responsive parenting may not detrimentally impact the emotional tenor of the home and parent child relationships [48-50]. The current study examined concurrent patterns of parents' reported experience from a national sample during the early months of the U.S. COVID-19 pandemic. Given the multifinality in the effect of parental mental health symptoms on children [47] and the protective influence of positive parent-child relationships [51], our research questions center on the potential linkages between mental health indicators and parents' report of child-parent relationship outcomes. Do we see associations from the sustained burden created 
by the COVID-19 pandemic on mothers' and fathers' relationships with their children? What role do mental health symptoms play? Informed by the spill-over hypothesis [10], we hypothesize that caregiver burden would be positively associated with parents' anxiety and depression symptoms with associations observed with parents' subsequent perceptions of their children's stress. Further, each of these stress and mental health variables would also be associated with parent-child relationship qualities, such that we would anticipate positive associations with conflict and negative associations with closeness.

\section{Methods}

Data presented here include the baseline survey results collected from April 27-28, 2020, approximately 5 weeks after the first U.S. quarantines were advised.

\section{Participants}

Adults 18 years or older living in the U.S. who speak English and were caring for a child under the age of 18 years old in their home at the time of survey administration were eligible to participate through the online worker pool Mechanical Turk (MTurk). MTurk workers have been reported as more diverse and otherwise fairly representative of the characteristics of larger online populations, including the U.S. at large [52, 53]. 420 caregivers (average age of 35.53 years) provided complete data for all key variables of interest (see measures below), $202(48.1 \%)$ of the study participants were female, and 117 (27.9\%) were of ethnic/racial minority including 45 (10.7\%) Black/African American respondents, 71(16.9\%) Asian/Asian American respondents, 14 (3.3\%) Hawaiian/Pacific Islander respondents, and 38 (9\%) of American Indian/Alaskan Native descent. Parents were asked to report the age of the focal child in the following categories: birth to 5 years old ( $\mathrm{n}=169,40.2 \%), 6$ to 11 years old $(n=146,34.8 \%)$, and 12 to 18 years old $(n=105,25 \%$; see Table 1 for further demographics details).

\section{Procedures}

All study materials were approved by the University of Connecticut IRB (X20-0075) prior to recruitment from MTurk's online worker pool for participation in the anonymous baseline study of family experiences and coping during the COVID-19 pandemic. MTurk has shown recruitment and
Table 1 Demographic characteristics

\begin{tabular}{|c|c|c|c|}
\hline & $\begin{array}{l}\text { Overall sample } \\
\mu(\mathrm{SD}) \\
\mathrm{N}(\%)\end{array}$ & $\begin{array}{l}\text { Male caregivers } \\
\mu(\mathrm{SD}) \\
\mathrm{N}(\%)\end{array}$ & $\begin{array}{l}\text { Female caregivers } \\
\mu(\mathrm{SD}) \\
\mathrm{N}(\%)\end{array}$ \\
\hline Age & $35.54(8.66)$ & & \\
\hline \multicolumn{4}{|l|}{ Gender } \\
\hline Male & - & $221(100 \%)$ & - \\
\hline Female & - & - & $204(100 \%)$ \\
\hline \multicolumn{4}{|l|}{ Race } \\
\hline Black/African American & $45(10.7 \%)$ & $27(12.4 \%)$ & $18(8.9 \%)$ \\
\hline Asian/Asian American & $71(16.9 \%)$ & $51(23.4 \%)$ & $20(9.9 \%)$ \\
\hline Native Hawaiian/other Pacific Islander & $14(3.3 \%)$ & $10(4.6 \%)$ & $4(2 \%)$ \\
\hline American Indian/Alaska Native & $38(9 \%)$ & $25(11.5 \%)$ & $13(6.4 \%)$ \\
\hline White & $303(72.1 \%)$ & $141(64.7 \%)$ & $162(80.2 \%)$ \\
\hline \multicolumn{4}{|l|}{ Ethnicity } \\
\hline LatinX & $81(19.3 \%)$ & $58(26.6 \%)$ & $23(11.4 \%)$ \\
\hline Non-LatinX & $339(80.7 \%)$ & $160(73.4 \%)$ & $179(88.6 \%)$ \\
\hline \multicolumn{4}{|l|}{ Partner status } \\
\hline Partnered & $357(85 \%)$ & $199(91.3 \%)$ & $158(78.2 \%)$ \\
\hline Non-partnered & $63(15 \%)$ & $19(8.7 \%)$ & $44(21.8 \%)$ \\
\hline \multicolumn{4}{|l|}{ Focal child age } \\
\hline Birth to 5 years old & $169(40.2 \%)$ & $105(48.2 \%)$ & $64(31.7 \%)$ \\
\hline 6 to 11 years old & $146(34.8 \%)$ & $74(33.9 \%)$ & $72(35.6 \%)$ \\
\hline 12 to 18 years old & $105(25 \%)$ & $39(17.9 \%)$ & $66(32.7 \%)$ \\
\hline \multicolumn{4}{|l|}{ Finances adequate to meet needs } \\
\hline Not met & $198(47.1 \%)$ & $101(46.3 \%)$ & $97(48 \%)$ \\
\hline Met & $222(52.9 \%)$ & $117(53.7 \%)$ & $105(52 \%)$ \\
\hline
\end{tabular}


data collection to be both replicable and valid [54]. Participants who consented to participate in the study and met inclusion criteria were able to complete the survey set and were compensated for their time.

\section{Measures}

Caregivers were asked to report demographic characteristics including gender, sexual orientation, race/ethnicity, caregiver age, age of focal child on whom caregivers based responses to key variables, partner status (from non-partnered: single, divorced or widowed, or partnered: married or living with a significant other), and financial security ("do you have enough money to meet your needs", rated from $1=$ not at all to $5=$ completely).

\section{Burden Scale for Family Caregivers (BSFC-s) [55]}

Burden Scale for Family Caregivers is a 10-item measure that assesses the perceived burden of caregiving responsibilities in the past 2 weeks using a 4-point Likert scale ranging from 0 "strongly disagree" to 3 "strongly agree". Example items include From time to time I wish I could "run away" from the situation I am in and The care takes a lot of my own strength. Items are summed to create a combined score ranging from 0 to 30; higher scores indicate increased burden levels. Categories of burden levels for this scale include: $0-4$ indicating mild to no burden, 5-14 indicating moderate burden, and scores from 15 to 30 indicate severe to very severe burden. Reported Cronbach's alphas are excellent $(\alpha=0.92)$ [55], as in the present study $(\alpha=0.94)$.

\section{Perceived Stress Scale—Child form [56]}

We used the National Institutes of Health Toolkit's emotion resources [57] for parent-reported child stress. The 10-item adaptation Cohen developed of the original Perceived Stress Scale [56] asked participants to report their perceptions of their child's general stress using a 5-point Likert scale from 0 "never" to 4 "Very often". Example items include How often have you felt that your child was unable to control the important things in their life and how often has your child felt nervous and stressed. Items are summed to create a combined score ranging from 0 to 40 ; higher scores indicate increased perceived stress. Reported Cronbach's alpha from a sample of parents of children as young as 8 years of age are good $(\alpha=0.87)$ [58], as are those for the current sample $(\alpha=0.81)$.

\section{Generalized Anxiety Disorder-7 (GAD-7) [59]}

The GAD-7 is a 7-item scale that assesses the severity of generalized anxiety symptoms and the associated disorder by rating the frequency of anxiety symptoms over the past 2 weeks using a 5-point Likert scale ranging from 0 "not at all" to 4 "nearly everyday". Example items include Feeling nervous, anxious or on edge and Worrying too much about different things. Items are summed to create a combined score ranging from 0 to 21 ; higher scores indicate greater presence of anxiety symptoms. Categories of levels of anxiety for this scale include: $0-5$ indicate minimal anxiety, 5-9 indicate mild anxiety, 10-14 indicate moderate anxiety, and 15-21 indicate severe anxiety [59]. Reported Cronbach's alphas are good $(\alpha=0.90)$ [59], and excellent in the current sample $(\alpha=0.93)$.

\section{Major Depression Inventory (MDI) [60]}

The MDI is a 12 -item scale that assesses depressive symptoms using a 6-point Likert scale ranging from 0 "At no time" to 5 "All of the time". Example items include Have you felt low in spirits or sad and Have you felt that life wasn't worth living. Items are summed to create a combined score ranging from 0 to 50 that represents overall severity of depression symptoms; higher scores indicate greater presence of depressed symptoms. Responses can be matched to diagnostic criteria to determine whether participants currently meet criteria for a major depressive episode [61]. Categories of levels of depression for this scale include: 20-24 for mild depression, 25-29 for moderate depression, and 30-50 for severe depression [62]. Reported Cronbach's alpha is excellent at 0.94 [60] and in the current sample $(\alpha=0.96)$.

\section{Child-Parent Relationship Scale (CPRS) [63]}

The CPRS is a 15 -item scale that assesses parents' views of their relationship with their child using a 5-point Likert scale ranging from 1 "definitely does not apply" to 5 "definitely applies". The CPRS contains two subscales, an 8-item conflict subscale that assesses the parents' perceived negativity in the parent-child relationship, and a 7 -item closeness subscale that assesses the parents' perception of the warmth, affection and open communication. Example items include Uncomfortable with physical affection and Will seek comfort from me if upset, from the conflict and closeness subscales, respectively. The scale is scored by summing items on the two subscales such that higher scores indicate greater perceived conflict or closeness, respectively. Reported Cronbach's alpha from samples of parents of children as young as 3 years of age for the two subscales are acceptable $(\alpha=0.83$ and 0.72 for conflict and closeness, respectively) [63], and are good 
in the current sample $(\alpha=0.85$ and 0.91 for conflict and closeness, respectively).

\section{Analyses}

Online survey data management guidelines suggest removing cases of substandard completion or inattentiveness, determined by abnormally quick response times [64, 65]. The average response time for this dataset was $34 \mathrm{~min}$, thus any entry which fell below the $10^{\text {th }}$ percentile or above the 90th percentile was examined for adequate completion. Two cases were deleted: one response fell below the 10th percentile, completing the survey set in under $5 \mathrm{~min}$, and the other took an excess of $50 \mathrm{~h}$. Data analysis concerning survey completion determined a lack of missing data among demographic variables or among measure scale scores; single item-level missingness was less than $0.1 \%$ across all key variables of interest such that no single-item was missing for more than a single participant. Given the lack of an interpretable pattern in missingness, missing data was determined to be missing completely at random. 12 cases were list-wise deleted for missing values among key variables of interest summed scores, and an additional 5 cases were deleted due to an outlier pattern detected in SPSS AMOS output. The resulting data set includes a total sample of 420 cases.

\section{Path Analysis}

Data were managed and the path analysis model developed in SPSS AMOS [66] using maximum likelihood estimation. The hypothesized path model examined the direct and indirect associations among caregiver burden, generalized anxiety, depression symptomology, perceived child stress, and child-parent conflict and closeness, with parent gender and focal child age categories as controls. A single model, multi-group path analysis was fit to the data. Groups were organized by parent gender, thus, there were two groups in the final analysis.

Model fit was evaluated by considering data from several fit indices. This was done to ensure that fit was evaluated fairly, and without temptation to select only the fit indices that provided the best interpretation for the model. Some have argued against the interpretation of fit indices other than the Chi square [67], as they are impacted by a number of factors in addition to the specification of the model. Others have cautioned against strict cutoffs for fit indices in that the use of strict cutoffs are often misapplied [68, 69]. Thus, we elected to examine and report the following indices with the associated cut off values as noted: Model Chi Square $p$ value of less than 0.05; GFI $>0.90$ for acceptable fit and $>0.95$ for good fit [70], CFI 0.90 for good fit [71], Root Mean Square Error of Approximation $<0.08$ for acceptable fit and $<0.05$ for good fit (RMSEA) [72].

\section{Results}

\section{Descriptive Results and Bivariate Associations}

Means for variables of interest were calculated to determine proportions of caregivers' responses that fell above or below relative reported cutoff points. Parents reported an average caregiver burden score of 11.00 , indicating moderate levels of burden [55], an average perceived child stress score of 23.79-which is above the 50th percentile of scores and indicates moderate stress [56]. The sample average for generalized anxiety was 7.59, indicating mild anxiety [59], and an average depression score of 19.16, indicating scores just below mild depression [62]. Average scores for child-parent relationship were 19.43 for conflict and 29.66 for closeness, where higher scores indicate greater perceived conflict or closeness, respectively [63]. These averages indicate both lower closeness and greater conflict compared to means from a national sample reported by the CPRS authors [63], these differences may be attributed to younger children sampled during normative circumstances for that study, rather than the present sample which was collected nationwide during a widespread community crisis.

Bivariate associations (see Table 2) indicate child-parent relationship conflict was significantly negatively associated with child-parent relationship closeness $(r=-0.37$, $\mathrm{p}<0.01)$. Importantly, additional positive associations exist between child-parent conflict and generalized anxiety, depression symptomology, caregiver burden, and
Table 2 Bivariate correlations among variables of interest for the overall sample $(n=420)$

\begin{tabular}{lllllll}
\hline & 1 & 2 & 3 & 4 & 5 & 6 \\
\hline Child-parent relationship-conflict & - & & & & \\
Child-parent relationship-close & $-.37^{* *}$ & - & & & \\
Generalized anxiety & $.56^{* *}$ & $-.17^{* *}$ & - & & \\
Depression & $.72^{* *}$ & $-.27^{* *}$ & $.88^{* *}$ & - & \\
Perceived child stress & $.75^{* *}$ & $-.47^{* *}$ & $.57^{* *}$ & $.67^{* *}$ & - & \\
Caregiver burden & $.58^{* *}$ & $-.31^{* *}$ & $.53^{* *}$ & $.62^{* *}$ & $.55^{* *}$ & - \\
\hline
\end{tabular}

$* * \mathrm{p}<.01$ 
parent perceived child stress $(r s=0.56$ to 0.75 , respectively, all $\mathrm{p}<0.01)$. Conversely, child-parent closeness was significantly negatively associated with generalized anxiety, depression, caregiver burden, and parent perceived child stress ( $r \mathrm{~s}=-0.17$ to -0.47 , respectively, all $\mathrm{p}<0.01)$. Independent samples $\mathrm{T}$-tests were then conducted to assess for group differences based on parent gender, financial resources, and single-parent status. Several statistically significant group differences are evident (see Table 3): male caregivers reported significantly higher rates of child-parent relationship conflict $(t=4.02, p<0.01)$, depression symptomology $(t=2.73, p<0.01)$, caregiver burden $(\mathrm{t}=2.02, \mathrm{p}<0.05)$, and parent perceived child stress $(t=4.86, p<0.01)$, whereas female caregivers reported significantly lower rates of child-parent relationship closeness $(\mathrm{t}=-4.90, \mathrm{p}<0.01)$. Caregivers whose financial needs were not met reported significantly higher rates of child-parent relationship conflict $(\mathrm{t}=4.21, \mathrm{p}<0.01)$, generalized anxiety $(\mathrm{t}=4.15, \mathrm{p}<0.01)$, depression symptomology $(\mathrm{t}=4.91$, $\mathrm{p}<0.01)$, caregiver burden $(\mathrm{t}=5.44, \mathrm{p}<0.01)$, and parent perceived child stress $(t=4.10, p<0.01)$, whereas parents whose financial needs were met reported significantly lower rates of child-parent relationship closeness $(t=-3.04$, $\mathrm{p}<0.05)$. Partnered parents reported significantly higher rates of child-parent relationship conflict $(\mathrm{t}=3.97, \mathrm{p}<0.01)$, generalized anxiety $(\mathrm{t}=2.65, \mathrm{p}<0.01)$, depression symptomology $(\mathrm{t}=2.29, \mathrm{p}<0.05)$, and parent perceived child stress $(t=2.72, p<0.01)$ compared to those without partners. Lastly, one-way ANOVA assessed differences on key variables by child focal age categories: parents of children ages 12 to 18 years old perceived less child stress $(\mathrm{F}=3.05$, $\mathrm{p}<0.05)$, and experienced lower caregiver burden $(\mathrm{F}=3.22$, $\mathrm{p}<0.05$ ) than parents of younger children (compared to birth to 5 year-olds and 6 to 11 year-olds).

\section{Path Analysis}

The results of a multi-group path analysis, organized by parent gender, is presented. Results are presented visually in Figs. 1 and 2, for male and female caregivers, respectively. The multi-group path model had good fit, $X^{2}(10)=159.04$, $\mathrm{p}<0.01, \mathrm{CFI}=.91, \mathrm{GFI}=0.92, \mathrm{RMSEA}=0.18$. Taken together, there is evidence of appropriate goodness of fit of the model to the data. The model Chi Square $p$ value was less than 0.05; and the GFI and CFI had values greater than 0.90. The RMSEA is slightly higher than ideal, but this may be an artifact of the complexity of the model. Some report that the index can be positively biased and that the bias towards a higher RMSEA is associated with both sample size and degrees of freedom [70]. Given that there are relatively few degrees of freedom, the RMSEA might be expected to be higher in this instance.

The multi-group model indicated no significant association between the control (focal child age) and any endogenous variables (parent perceived child stress, child parent relationship conflict and child parent relationship closeness). Figures 1 and 2 represent the path analyses for male and female caregivers, respectively. Solid lines indicate

Table 3 Means, standard deviations, and group difference effect sizes for the overall sample $(n=420)$

\begin{tabular}{|c|c|c|}
\hline Variable & $\mathrm{M}(\mathrm{SD})$ & Group differences (effect size) \\
\hline Child-parent conflict & $19.43(8.44)$ & $\begin{array}{l}\text { Reported more by men than women }(\mathrm{d}=0.39) \\
\text { Reported more by caregivers whose financial needs are not met }(\mathrm{d}=0.41) \\
\text { Reported more by partnered caregivers }(\mathrm{d}=0.59)\end{array}$ \\
\hline Child-parent closeness & $29.66(4.56)$ & $\begin{array}{l}\text { Reported more by women than men }(d=0.48) \\
\text { Reported more by caregivers whose financial needs are met }(d=0.29)\end{array}$ \\
\hline Generalized anxiety & $7.59(6.01)$ & $\begin{array}{l}\text { Reported more by caregivers whose financial needs are not met }(d=0.40) \\
\text { Reported more by partnered caregivers }(d=0.38)\end{array}$ \\
\hline Depression & $19.16(17.06)$ & $\begin{array}{l}\text { Reported more by men than women }(d=0.27) \\
\text { Reported more by caregivers whose financial needs are not met }(d=0.48) \\
\text { Reported more by partnered caregivers }(d=0.33)\end{array}$ \\
\hline Perceived child stress & $23.79(6.88)$ & $\begin{array}{l}\text { Reported more by men than women }(\mathrm{d}=0.47) \\
\text { Reported more by caregivers whose financial needs are not met }(\mathrm{d}=0.40) \text {; } \\
\text { Reported more by partnered caregivers }(\mathrm{d}=0.39) \\
\text { Reported less for parents of } 12-18 \text { year-olds compared to younger groups }(\mathrm{F}=3.05) \text {; } \\
\text { Significantly negatively associated with parent age }(\mathrm{r}=-0.13)\end{array}$ \\
\hline Caregiver burden & $11.00(8.03)$ & $\begin{array}{l}\text { Reported more by men than women }(\mathrm{d}=0.20) \\
\text { Reported more by caregivers whose financial needs are not met }(\mathrm{d}=0.53) \\
\text { Reported less for parents of } 12-18 \text { year-olds compared to younger groups }(\mathrm{F}=3.22)\end{array}$ \\
\hline
\end{tabular}

Two-tailed independent samples T-tests were used for categorical group comparisons; One-way ANOVA was used for group categorizations with three or more groups (focal child age: birth to 5 years old, 6 to 11 years old, and 12 to 18 years old); bivariate correlations were used for continuous predictors (age). Standardized effect sizes for group difference tests are based upon Cohen's d $(0.20=s m a l l, 0.50=$ medium, $0.80=$ large $)$; Pearson's $r$ is used for all bivariate correlations $(.1=$ small, $.3=$ medium, $.5=$ large $)$ 
Fig. 1 Model of male caregivers' burden with standardized path estimates $(n=221)$. Dashed lines indicate nonsignificant paths

Fig. 2 Model of female caregivers' burden with standardized path estimates $(n=204)$. Dashed lines indicate nonsignificant paths

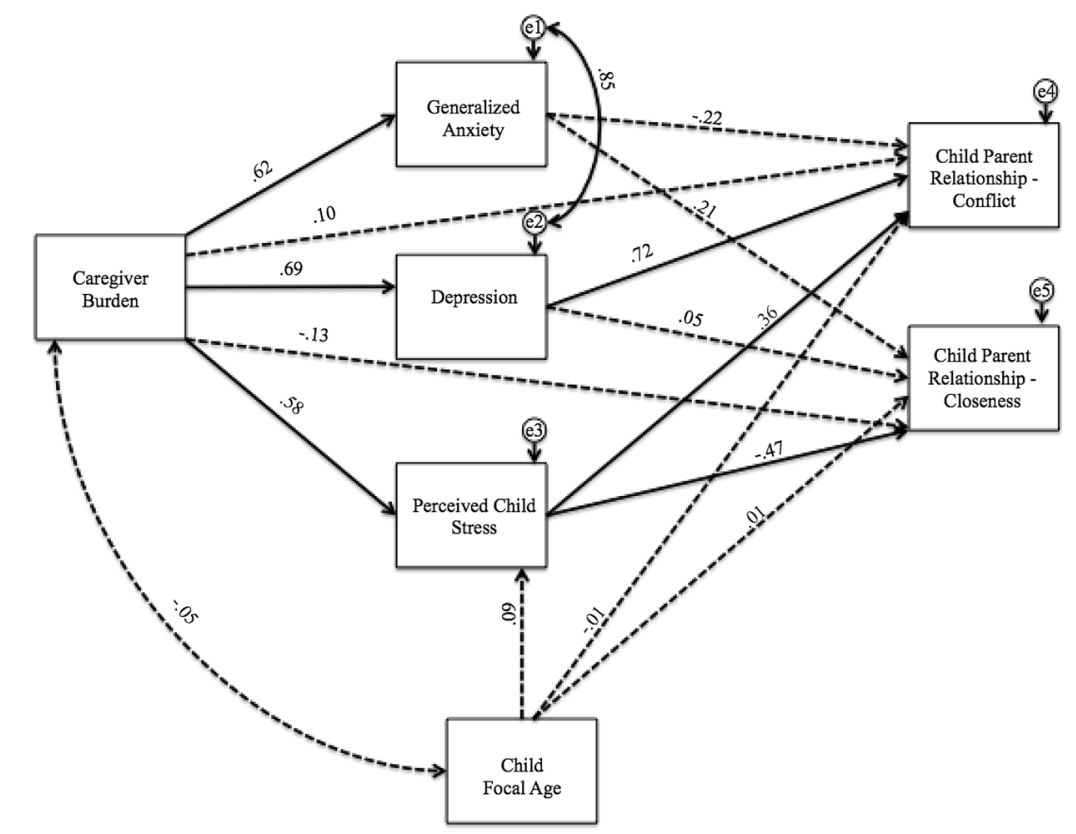

Note. Dashed lines indicate non-significant paths.

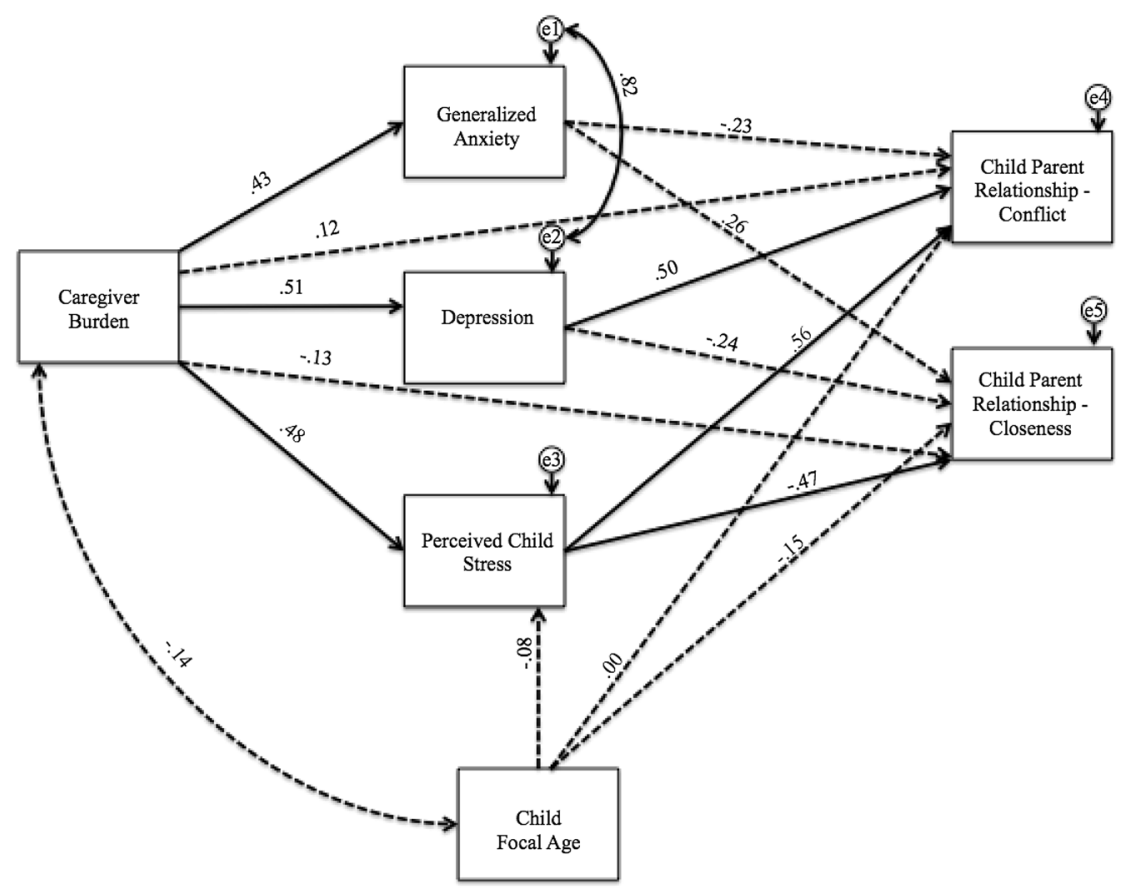

Note. Dashed lines indicate non-significant paths. significant paths and dashed lines indicate non-significant paths. The path model indicates that caregiver burden directly predicts parents' generalized anxiety, depression symptomology, and parent perceived child stress, but does not directly predict child parent relationship conflict and closeness. This model indicates that caregiver burden indirectly predicts child parent relationship conflict and closeness through parents generalized anxiety, depression symptomology, and parent perceived child stress. 


\section{Caregiver Burden}

As hypothesized, caregiver burden was positively associated with generalized anxiety $(\beta=0.62$ and 0.43$)$, depression symptomology $(\beta=0.69$ and 0.51$)$, and parent perceived child stress $(\beta=0.58$ and 0.48$)$ for male and female caregivers, respectively; these results indicate the predictive associations between variables of interests was consistently greater for male caregivers. Parents who reported higher rates of caregiver burden also reported higher rates of generalized anxiety, depression, and parent perceived child stress, with male caregivers reporting higher rates overall than female caregivers. Caregiver burden was not significantly directly associated with child parent relationship conflict ( $\beta=0.10$ and $0.12, p=n s)$ or child parent relationship closeness $(\beta=-0.13$ and $-0.13, p=n s)$ for male or female caregivers, respectively.

\section{Generalized Anxiety}

Contrary to our hypothesis, generalized anxiety symptoms did not significantly predict child parent relationship conflict $(\beta=-0.22$ and $-0.23, p<0.01)$ or child parent relationship closeness $(\beta=0.21$ and $0.26, p=n s)$ for male or female caregivers, respectively.

\section{Depression}

As hypothesized, depression symptomology was significantly positively associated with child parent relationship conflict $(\beta=0.72$ and $0.50, p<0.01)$ for male and female caregivers, respectively, suggesting caregivers with increased depression symptoms reported increased conflict in their parent-child relationship, more so for male caregivers in our sample. Contrary to our hypothesis, depression symptoms were not significantly associated with child parent relationship closeness $(\beta=0.05$ and $-0.24, p=n s)$ for male and female caregivers, respectively.

\section{Parent Perceived Child Stress}

As hypothesized, parents' reports of increased perceived child stress were significantly positively associated with child parent relationship conflict $(\beta=0.36$ and 0.56 , $\mathrm{p}<0.01$ ) for male and female caregivers, respectively, suggesting caregivers who perceived greater child stress were more likely to report increased conflict in their child-parent relationship, particularly for female caregivers. Additionally, parents' increased reports perceived child stress was significantly negatively associated with child parent relationship closeness $(\beta=-0.47$ and $-0.47, \mathrm{p}<0.01)$ for male and female caregivers, respectively, suggesting caregivers, regardless of their gender, with increased perceptions of child stress were more likely to report reduced closeness in their parent-child relationship.

\section{Discussion}

Aligned with recent data from the U.S. Census Bureau and Centers for Disease Control indicating that mental health symptoms are increasing during COVID-19 (anxiety more so than depression) [73], the parents in this sample report comparable mental health symptoms that echo rates from a national sample of caregivers during the COVID-19 pandemic [8]. Parenting is stressful under normative circumstances-its stresses felt by men and women [40, 74], but crucial time-sensitive data indicate that COVID-19 has led to significant increases in the population's general stress, a change felt even more acutely for parents than their non-parent counterparts $[8,75]$. Our data are among the first to report subgroup differences among parents during COVID-19, indicating fathers in our sample report higher rates of burden overall. Further, as seen in the Betas for each path, the predictive values between variables at each step of the model are strongest for male caregivers. This is in contrast to reports prior to COVID-19 that indicate mothers report a disproportionate level of caregiving responsibility and greater caregiver burden than their male counterparts [76-78], which may suggest difficulty in adjusting to disaster-related shifts in roles and responsibilities for men. The consistently higher beta weights for men's paths indicates that the associations between caregiver burden and mental health symptoms and perceived child stress, and subsequent linkages to relationship quality are stronger than they are for women. While caregiving roles and responsibilities have increased for all parents by dint of school and childcare closures during the pandemic, women appear to be less distressed by these shifts or note increased conflict and decreased closeness with their children (regardless of the extent of relative change in caregiving roles). Similarly, we note significantly higher rates of reported caregiver burden among the nearly half of the sample who indicate a lack of financial resources adequate to meet needs, highlighting the potential heightened mental health needs of known economically vulnerable segments of the population noted by similar COVID-19 surveys of the general population $[5,75]$.

Path analysis results report of significant linkages between parents' caregiver burden and mental health and perceptions of children's stress; these in turn are significantly linked to child-parent closeness and conflict. These findings are in line with parent reports of children's 
experiences from disasters in which the degree of variability in outcomes may be partially explained by children's understanding of the crises at hand and their families' response [79, 80]. As noted by Lansford et al. [81] when describing how children respond to parenting, "[c] hildren's conceptions derive at least in part from norms and expectations gleaned from the broader context in which families are situated" (p. 203). Given the pervasive, community-wide experience of heightened stress during COVID-19, children may be observing context-specific norms for their relationships with parents through the creation of new routines, rules, and expectations during the quarantine and shelter-in-place circumstances. Parents are contending with the indefinite parameters of a disaster expected to reach high mortality rates nationwide before the end of children's school year. Anxieties about COVID19 fueled municipal recommendations to close workplaces and schools adding caregiving and education challenges to the daily routine adjustments parents must make with very little support [7].

Parents reporting higher levels of depression and anxiety in this sample also report higher stress in their children; perhaps this effect is driven by the distortion or overreporting tendency noted by previous researchers [44, 82]. Such a result is possible for a number of reasons, for example, parents might overreport child stress out of worry, or fear, or as a result of projection of their own mental health difficulties. Or, it is possible that the entire family's coping skills have been challenged and everyone is suffering from an increase in mental health concerns. Similarly, the significant group differences between single and partnered parents suggests that the additional demands of managing a co-parenting relationship may be influencing child-parent relationships. Future research which untangles sources of relationship stress, and includes partners and children perspectives, would be useful.

While the model represents a sound fit to the data, there are some areas of concern that require additional examination. The CFI and GFI indices indicate good fit [70], while the RMSEA does not. It is possible that the RMSEA may be less robust for this model, given noted limitations (e.g., small dfs and sample size, or model misspecifications) [83]. RMSEA is most accurately a measure of badness of fit [84], and, as a result, it should be interpreted with caution here. Nonetheless, there is the potential that the RMSEA has identified some potential misspecification in the model, and future researchers might wish to examine these constructs with different paths, or in other ways that provide more data about associations between these variables.

Results presented here provide time-sensitive information about families' experiences during the first weeks of the COVID-19-pandemic, however, several limitations should be noted. While we lack a pre-pandemic baseline assessment from this sample, our results provide a description of families' early experiences during the peak of the COVID-19 pandemic; stronger inferences beyond those possible with cross-sectional data require longitudinal data. While the NIH toolkit resources are valuable for creating low-burden, shared data elements for the field of child development, in many cases they are recent adaptations and require further validation [57]. Specifically, while Cohen's assessment of perceived stress is among the most commonly used global stress measures [56], the adaptation used in this study has not yet been tested in children younger than 8 years of age. MTurk recruitment enables rapid collection of data on a national scale, however, caution is warranted with regards to the sample's generalizability (specifically, the majority of the sample is white and has access to the internet that facilitate MTurk data collection). While $47 \%$ of this sample reported financial resources insufficient to meet their needs, deliberate recruitment of vulnerable families (e.g., those with chronic medical conditions or complex educational needs), including more robust measures of resources and supportive services in use, would better estimate heightened risk for those at greatest risk for mental health difficulties. Results from this MTurk sample may not be as representative as those from a probability sample, but nevertheless are among the first national data available on the compounded stresses brought to bear upon American parents during COVID-19.

Attending to mental health indicators for parents is vital for the agile provision of mental health resources to protect high quality parent-child interactions despite the stressful context of the COVID-19 pandemic. This study highlights the important spillover link between mental health (i.e., depression, anxiety), perceptions of children's stress, and subsequent impacts on child-parent relationships [10, 82]. Clear links exist between mental health indicators and childparent conflict and closeness, such that parents with more severe depression symptoms and who perceive greater child stress also report greater conflict and less closeness, those with more severe anxiety symptoms report less conflict, echoing findings by Ginsburg, Grover and LaLongo [85] that suggest anxious parents may be particularly vigilant to responding to cues of children's distress by encouraging them to express their opinions and providing support and acceptance of their decisions. The pattern of affect and behavior that can carry over from parents to children may take several forms, per the spillover hypothesis [10]: The spillover hypothesis suggests that affect or behavior can transfer within a family system at the same valence, or through compensatory paths that occur with the opposite valence, or finally through a crossover process, where rather than a transfer of affect within one person across subsystems, crossover describes the transfer of affect or behavior between 
people. Our results indicate possible spillover effects for depressed parents and compensatory effects for anxious parents, however, future data on the experiences of other members in the family will help elucidate more precisely the extent of impacts from each form of spillover (e.g., co-parent reports of partner and child-parent relationships).

Should fatigue and the emotional strains of quarantine and social distance (and related changes in work, education, and child care routines) increase over time, practitioners will need to be focused on providing resources to bolster the energy caregivers have to sustain positive parenting behaviors and provide sensitive interactions for their children that convey a sense of safety, precaution, and protection. These resources may specifically benefit caregivers experiencing heightened anxiety or depression symptoms, as was the case for fathers in this sample. It may be particularly helpful to attend to the demands that new shifts in caregiving roles and responsibilities place on fathers who may be less unaccustomed to navigating the added tasks of work-life balance during times of stress. Supportive resources that structure and protect time for self-care that emphasize its value while not stigmatizing help-seeking (formal or informal) may prove especially reassuring to this group.

\section{Summary}

Research indicates that exposure to a wide range of disasters negatively impacts mental health for families and can lead to prolonged periods of increased anxiety and depression symptoms. Further evidence suggests that child disaster outcomes are worst among children of highly distressed caregivers, or those caregivers who experience their own negative mental health outcomes from the disaster. The impact of millions of families sheltering in place for an undefined period of time, during the current pandemic, may lead to unprecedented impacts on individuals' mental health with unknown impacts on child-parent relationships; periods of uncertainty with an indeterminant endpoint constitute a stressful experience with particular salience for children. The current study used path analysis to examine concurrent patterns of parents' $(n=420)$ experience from a national sample during the early months of the U.S. COVID-19 pandemic. The results of a multigroup path analysis, organized by parent gender, indicates good fit to the data $\left[X^{2}(10)=159.04, p<0.01\right]$, such that parents who reported higher rates of caregiver burden also reported higher rates of generalized anxiety, depression, and parent perceived child stress, with male caregivers reporting higher rates overall than female caregivers and stronger associations across the linkages between variables at each step in the model. Specifically, there are significant linkages between parents' caregiver burden, mental health, and perceptions of children's stress; these in turn are significantly linked to child-parent closeness and conflict, such that the strongest betas are seen for male caregivers across all variables of interest. These associations are indicative of spillover effects for depressed parents and compensatory effects for anxious parents. In light of these findings, mental health providers and family support professionals can adapt their treatment approaches for parents to address the potential for anxiety and depression to impact parents' perceptions of their children's experience and the consequences that may have on parent-child relationship quality.

\section{References}

1. Gorbalenya AE, Baker SC, Baric RS et al (2020) The species severe acute respiratory syndrome-related coronavirus: classifying 2019-nCoV and naming it SARS-CoV-2. Nat Microbiol 5:536-544. https://doi.org/10.1038/s41564-020-0695-z

2. Layne SP, Hyman JM, Morens DM, Taubenberger JK (2020) New coronavirus outbreak: framing questions for pandemic prevention. Sci Transl Med 12:eabb1469

3. Solomon HV (2020) COVID-19 checklist: mask, gloves, and video chatting with grandpa. Psychiatry Res 288:e112986

4. Stokes EK, Zambrano LD, Anderson KN et al (2020). Coronavirus Disease 2019 Case Surveillance — United States, January 22-May 30, 2020. Morb Mortal Wkly Rep 69:759-765

5. Park, CL, Russell, BS, Fendrich, M, Finkelstein-Fox, L, Hutchison, M, Becker, J (2020). Americans' Covid-19 stress, coping, and adherence to CDC guidelines. J Gen Int Med. https://doi. org/10.1007/s11606-020-05898-9

6. Cluver L, Lachman JM, Sherr L, Wessels I, Krug E, Rakotomalala S, Blight S, Hillis S, Bachmand G, Green O, Butchart A (2020) Parenting in a time of COVID-19. Lancet 395:e64

7. Pew Research Center (2020). Covid 19: effect on personal life. https://www.pewresearch.org/pathways-2020/CVCHILDCARE/ total_us_adults/us_adults. Accessed 28 July 2020

8. Russell, BS, Hutchison, M, Tambling, R, Tomkunas, AJ, Horton, AL (2020). Initial challenges of caregiving during COVID-19: Caregiver burden, mental health, and the parent-child relationship. Child Psychiatry Hum Dev. https://doi.org/10.1007/s1057 8-020-01037-x

9. Katz LF, Gottman JM (1996) Spillover effects of marital conflict: In search of parenting coparenting mechanisms. In: McHale JP, Cowan PA (eds) Understanding how family-level dynamics affect children's development: studies of two-parent families. JosseyBass, San Francisco, pp 57-76

10. Nelson JA, O'Brien M, Blankson AN, Calkins SD, Keane SP (2009) Family stress and parental responses to children's negative emotions: Tests of the spillover, crossover, and compensatory hypotheses. J Fam Psychol 23(5):671-679. https://doi. org/10.1037/a0015977

11. North CS (2016) Disaster mental health epidemiology: methodological review and interpretation of research findings. Psychiatry Interpers Biol Processes 79:130-146. https://doi. org/10.1080/00332747.2016.1155926

12. Mervosh S, Lu D, Swales V (2020). See which states and cities have told residents to stay home. The New York Times.https:// www.nytimes.com/interactive/2020/us/coronavirus-stay-at-homeorder.html. Accessed 28 July 2020

13. Education Week (2020). Map: coronavirus and school closures. https://www.edweek.org/ew/section/multimedia/map-coronaviru s-and-school-closures.html. Accessed 28 July 2020 
14. Galea S, Merchant RM, Lurie N (2020) The mental health consequences of COVID-19 and physical distancing: the need for prevention and early intervention. JAMA Intern Med. https://doi. org/10.1001/jamainternmed.2020.1562

15. Horesh D, Brown AD (2020) Traumatic stress in the age of COVID-19: a call to close critical gaps and adapt to new realities. Psychol Trauma 12:331-335. https://doi.org/10.1037/tra0000592

16. Bolt MA, Helming LM, Tintle NL (2018) The associations between self-reported exposure to the chernobyl nuclear disaster zone and mental health disorders in Ukraine. Front Psychiatry. https://doi.org/10.3389/fpsyt.2018.00032

17. Fussell E, Lowe SR (2014) The impact of housing displacement on the mental health of low-income parents after hurricane Katrina. Soc Sci Med 113:137-144

18. Labarda CE, Jopson QDQ, Hui VK, Chan CS (2020) Long-term displacement associated with health and stress among survivors of typhoon Haiyan. Psychol Trauma. https://doi.org/10.1037/tra00 00573

19. Seto M, Nemoto H, Kobayashi N, Kikuchi S, Honda N, Kim Y et al (2019) Post-disaster mental health and psychosocial support in the areas affected by the great east japan earthquake: a qualitative study. BMC Psychiatry 19:261

20. Sprague CM, Kia-Keating M, Felix E, Afifi T, Reyes G, Afifi W (2015) Youth psychosocial adjustment following wildfire: the role of family resilience, emotional support, and concrete support. Child Youth Care Forum 44(3):433-450. https://doi.org/10.1007/ s10566-014-9285-7

21. Kerns CE, Elkins RM, Carpenter AL, Chou T, Green JG, Comer JS (2014) Caregiver distress, shared traumatic exposure, and child adjustment among area youth following the 2013 Boston marathon bombing. J Affect Disord 167:50-55

22. Kılıç C, Kılıç EZ, Aydın İO (2011) Effect of relocation and parental psychopathology on earthquake survivor-children's mental health. J Nerv Ment Dis 199:335-341. https://doi.org/10.1097/ NMD.0b013e3182174ffa

23. Masten AS, Narayan AJ (2012) Child development in the context of disaster, war, and terrorism: Pathways of risk and resilience. Annu Rev Psychol 63:227-257

24. Brooks SK, Webster RK, Smith LE, Woodland L, Wessely S, Greenberg N, Rubin GJ (2020) The psychological impact of quarantine and how to reduce it: rapid review of the evidence. Lancet 395(10227):912-920. https://doi.org/10.1016/S0140 $-6736(20) 30460-8$

25. Hawryluck L, Gold WL, Robimson S, Pogorski S, Galea S, Styra R (2004) SARS control and psychological effects of quarantine, Toronto, Canada. Emerg Infect Dis 10:1206-1212

26. Carleton NK (2016) Into the unknown: a review and synthesis of contemporary models involving uncertainty. J Anxiety Disord 39:30-43

27. Sweeny K (2018) On the experience of awaiting uncertain news. Curr Dir Psychol Sci 27:281-285. https://doi.org/10.1177/09637 21417754197

28. Ellis DM, Hudson JL (2010) The metacognitive model of generalized anxiety disorder in children and adolescents. Clin Child Fam Psychol Rev 13:151-163

29. Wisner B, Paton D, Alisic E, Eastwood O, Shreve C, Fordham M (2018) Communication with children and families about disaster: reviewing multi-disciplinary literature 2015-2017. Curr Psychiatry Rep 20:73

30. Maeda M, Oe M (2017) Mental health consequences and social issues after the Fukushima disaster. Asia Pac J Public Health 29:36S-46S

31. Kliewer W, Fearnow MD, Miller PA (1996) Coping socialization in middle childhood: tests of maternal and paternal influences. Child Dev 67(5):2339-2357
32. Shipman KL, Schneider R, Fitzgerald MM, Sims C, Swisher L, Edwards A (2007) Maternal emotion socialization in maltreating and non-maltreating families: implications for children's emotion regulation. Soc Dev 16(2):268-285. https://doi.org/10.111 1/j.1467-9507.2007.00384.x

33. Juth V, Silver RC, Seyle DC, Widyatmoko CS, Tan ET (2015) Post-disaster mental health among parent-child dyads after a major earthquake in Indonesia. J Abnorm Child Psychol 43:13091318. https://doi.org/10.1007/s10802-015-0009-8

34. Carpenter AL, Elkins RM, Kerns C, Chou T, Green JG, Comer JS (2017) Event-related household discussions following the Boston marathon bombing and associated posttraumatic stress among area youth. J Clin Child Adolesc Psychol 46:331-342. https://doi. org/10.1080/15374416.2015.1063432

35. Greene CA, McCarthy KJ, Estabrook R, Wakschlag LS, BriggsGowan MJ (2020) Responsive parenting buffers the impact of maternal PTSD on young children. Parent: Sci Pract 20:141-165

36. Taraban L, Shaw DS (2018) Parenting in context: revisiting Belsky's classic process of parenting model in early childhood. Dev Rev 48:55-81

37. Bornstein MH, Tamis-LeMonda CS, Hahn C-S, Haynes OM (2008) Maternal responsiveness to young children at three ages: longitudinal analysis of a multidimensional, modular, and specific parenting construct. Dev Psychol 44(3):867-874. https:// doi.org/10.1037/0012-1649.44.3.867

38. Eshel N, Daelmans B, Carbral de Mello M, Martines J (2006) Responsive parenting: interventions and outcomes. Bull World Health Organ 84(12):991-998. https://doi.org/10.2471/ BLT.06.030163

39. Pastorelli C, Lansford JE, Luengo Kanacri BP, Malone PS, Di Giunta L, Bacchini D, Bombi AS, Zelli A, Miranda MC, Bornstein MH, Tapanya S (2016) Positive parenting and children's prosocial behavior in eight countries. J Child Psychol Psychiatry 57(7):824-834. https://doi.org/10.1111/jcpp.12477

40. Deater-Deckard K (2008) Parenting stress. Yale University Press, New Haven

41. Masten A (2018) Resilience theory and research on children and families: past, present, and promise. J Fam Theory Rev 10(1):12-31. https://doi.org/10.1111/jftr.12255

42. Granek L, Rosenberg-Yunger ZR, Dix D, Klaassen RJ, Sung L, Cairney J, Klassen AF (2012) Caregiving, single parents and cumulative stresses when caring for a child with cancer. Child Care Health Dev 40:184-194. https://doi.org/10.1111/ cch. 12008

43. Martinez-Marcos M, De la Cuesta-Benjumea C (2015) Women's self-management of chronic illnesses in the context of caregiving: a grounded theory study. J Clin Nurs 24:1557-1566

44. Briggs-Gowan MJ, Carter AS, Schwab-Stone M (1996) Discrepancies among mother, child, and teacher reports: examining the contributions of maternal depression and anxiety. J Abnorm Child Psychol 24:749-765

45. Schechter DS, Willheim E, Hinojosa C, Scholfield-Kleinman K, Turner JB, McCaw J, Zeanah Jr CH, Myers MM (2010) Subjective and objective measures of parent-child relationship dysfunction, child separation distress, and joint attention. Psychiatry 73(2):130-144. https://doi.org/10.1521/psyc.2010.73.2.130

46. Van Ee E, Kleber R, Mooren TTM (2012) War trauma lingers on: Associations between maternal posttraumatic stress disorder, parent-child interaction, and child development. Infant Mental Health J 33(5):459-468. https://doi.org/10.1002/imhj.21324

47. Lambert JE, Holzer J, Hasbun A (2014) Association between parents' PTSD severity and children's psychological distress: a meta-analysis. J Trauma Stress 27(1):1-9. https://doi.org/10.1002/ jts. 21891

48. Darling N, Steinberg L (1993) Parenting style as context: an integrative model. Psychol Bull 113:487-496 
49. Labella MH, Narayan AJ, Masten AS (2016) Emotional climate in families experiencing homelessness: associations with child affect and socioemotional adjustment in school. Soc Dev 25:304-321

50. Morris A, Silk JS, Steinberg L, Myers SS, Robinson LR (2007) The role of family context in the development of emotion regulation. Soc Dev 16:338-361

51. Masten AS, Best KM, Garmezy N (1990) Resilience and development: contributions from the study of children who overcome adversity. Dev Psychopathol 2(4):425-444. https://doi. org/10.1017/S0954579400005812

52. Bartneck C, Deunset A, Moltchanova E, Zawieska K (2015) Comparing the similarity of responses received from studies in Amazon's Mechanical Turk to studies conducted online and with direct recruitment. PLoS ONE 10:1-23

53. Sheehan KB, Pittman M (2016) Amazon's mechanical Turk for academics: the HIT handbook for social science research. Melvin \& Leigh, Irvine

54. Mortensen K, Hughes TL (2018) Comparing Amazon's mechanical turk platform to conventional data collection methods in the health and medical research literature. J Gen Intern Med 33:533-538

55. Graessel E, Berth H, Lichte T, Grau H (2014) Subjective caregiver burden: validity of the 10-item short version of the Burden Scale for family caregivers BSFC-s. BMC Geriatr 14:23. https://doi. org/10.1186/1471-2318-14-23

56. Cohen S, Kamarck T, Mermelstein R (1983) A global measure of perceived stress. J Health Soc Behav 24:386-396

57. Beaumont JL, Havlik R, Cook KF, Hays RD, Wallner-Allen K et al (2013) Norming plans for the NIH Toolbox. Neurology 80(11 S3):S87-S92

58. Salsman JM, Butt ZA, Pilkonis PC, Cyranowski JJ, Zill NR, Hendrie HK et al (2013) Emotion assessment using the NIH Toolbox. Neurology 80(113):S76-S86. https://doi.org/10.1212/WNL.0b013 e3182872e11

59. Spitzer RL, Kroenke K, Williams JB, Löwe B (2006) A brief measure for assessing generalized anxiety disorder: the GAD-7. Arch Intern Med 166:1092-1097

60. Bech P, Rasmussen NA, Olsen LR, Noerholm V, Abildgaard W (2001) The sensitivity and specificity of the major depression inventory, using the present state examination as the index of diagnostic validity. J Affect Disord 66(2):159-164. https://doi. org/10.1016/s0165-0327(00)00309-8

61. American Psychiatric Association (2013) Avoidant personality disorder. In Diagnostic and statistical manual of mental disorders, 5th edn. American Psychiatric Association, Arlington. https://doi. org/10.1176/appi.books.9780890425596

62. Olsen LR, Jensen DV, Noerholm V, Martiny K, Bech P (2003) The internal and external validity of the major depression inventory in measuring severity of depressive states. Psychol Med 33:351-356

63. Driscoll K, Pianta RC (2011) Mothers' and fathers' perceptions of conflict and closeness in parent-child relationships during early childhood. J Early Child Infant Psychol 7:1-24

64. Kees J, Berry C, Burton S, Sheehan K (2017) An analysis of data quality: professional panels, student subject pools, and Amazon's mechanical Turk. J Advert 46:141-155

65. Sheehan KB (2018) Crowdsourcing research: data collection with Amazon's mechanical turk. Commun Monogr 85:140-156

66. Arbuckle JL (2019) Amos (version 26.0) [computer program]. IBM SPSS, Chicago

67. Barrett PT (2007) Structural equation modelling: adjudging model fit. Personal Individ Differ 42(5):815-824. https://doi. org/10.1016/j.paid.2006.09.018

68. Hayduk LA, Cummings GC, Boadu K, Pazderka-Robinson H, Boulianne S (2007) Testing! testing! one, two, three: testing the theory in structural equation models! PERSONAL Individ Differ 42(5):841-850
69. Hu LT, Bentler PM (1999) Cutoff criteria for fit indexes in covariance structure analysis: conventional criteria versus new alternatives. Struct Equ Model 6:1-55

70. Hooper D, Coughlan J, Mullen M (2007) Structural equation modeling: Guidelines for determining model. Electron J Bus Res Methods 6:53-60

71. Bentler PM (1990) Comparative fit indexes in structural models. Psychol Bull 107:238-246. https://doi. org/10.1037/0033-2909.107.2.23

72. Steiger JH (1990) Structural model evaluation and modification: an interval estimation approach. Multivar Behav Res 25:173-180. https://doi.org/10.1207/s15327906mbr2502_4

73. National Center for Health Statistics (2020). Mental health: household pulse survey. https://www.cdc.gov/nchs/covid19/pulse/menta 1-health.htm. Accessed 28 July 2020

74. Mikolajczak M, Raes M, Avalosse H, Roskam I (2018) Exhausted parents: sociodemographic, child-related, parent-related, parenting and family-functioning correlates of parental burnout. J Child Fam Stud 27(2):602-614. https://doi.org/10.1007/s1082 6-017-0892-4

75. American Psychological Association (2020). Stress in the time of COVID-19. https://www.apa.org/news/press/releases/stress/2020/ report. Accessed 28 July 2020

76. Blanchard LT, Gurka MG, Blackman JA (2006) Emotional, developmental, and behavioral health of American children and their families: a report from the 2003 National Survey of Children's Health. Pediatrics 117(6):e1202-e1212. https://doi.org/10.1542/ peds.2005-2606

77. Cohen MS (1999) Families coping with childhood chronic illness: a research review. Fam Syst Health 17:149-164. https://doi. org $/ 10.1037 / \mathrm{h} 0089879$

78. Pinquart M, Sörensen S (2006) Gender differences in caregiver stressors, social resources, and health: an updated meta-analysis. J Gerontol B 61:33-45. https://doi.org/10.1093/geronb/61.1.P33

79. Samuelson KW, Wilson CK, Padron E, Lee S, Gavron L (2017) Maternal PTSD and children's adjustment: parenting stress and emotional availability as proposed mediators. J Clin Psychol 73(6):693-706. https://doi.org/10.1002/jclp.22369

80. Wickrama KAS, Kaspar V (2007) Family context of mental health risk in Tsunami-exposed adolescents: findings from a pilot study in Sri Lanka. Soc Sci Med 64(3):713-723. https://doi. org/10.1016/j.socscimed.2006.09.031

81. Lansford JE, Bornstein MH, Deater-Deckard K, Dodge KA, Al-Hassan SM, Bacchini D, Bombi AS, Chang L, Chen BB, Di Giunta L, Malone PS (2016) How international research on parenting advances understanding of child development. Child Dev Perspect 10:202-207

82. Richters JE (1992) Depressed mothers as informants about their children: a critical review of the evidence for distortion. Psychol Bull 112:485-499

83. Taasoobshirazi G, Wang S (2016) The performance of the SRMR, RMSEA, CFI, and TLI: an examination of sample size, path size, and degrees of freedom. J Appl Quant Methods 11(3):31-39

84. Kline RB (2010) Principles and practice of structural equation modeling, 3rd edn. Guilford Press, New York

85. Ginsburg GS, Grover RL, LaLongo N (2005) Parenting behaviors among anxious and non-anxious mothers: relation with concurrent and long-term child outcomes. Child Fam Behav Ther 26:23-41. https://doi.org/10.1300/J019v26n04_02

Publisher's Note Springer Nature remains neutral with regard to jurisdictional claims in published maps and institutional affiliations. 